\title{
Knowledge of Postgraduate Medical Trainees Regarding Epidemiology
}

\author{
Shoaib Shafi ${ }^{1}$, Tayyaba Faisal ${ }^{2}$, Sajida Naseem ${ }^{3}$, Sajida Javed ${ }^{4}$, Haider Ghazanfar ${ }^{5}$ \\ 1. Medicine, College of Physician and Surgeons Pakistan 2. Research Evaluation Unit, Regional Center \\ Islamabad, College of Physician and Surgeons Pakistan 3. Community and Family Medicine, Shifa \\ International Hospital, Islamabad, PAK 4. Publications, Army Medical College, Rawalpindi 5. Internal \\ Medicine, Shifa College of Medicine, Islamabad, PAK
}

$\square$ Corresponding author: Tayyaba Faisal, drtayyabafaisal@gmail.com

Disclosures can be found in Additional Information at the end of the article

\section{Abstract}

\section{Introduction}

An understanding of epidemiology is fundamental for designing research and understanding evidence-based medicine (EBM). The purpose of our study was to determine the knowledge of epidemiology among postgraduate medical trainees.

\section{Methods}

We carried out a cross-sectional study from January 2017 to June 2017 at the Regional Centre Islamabad, College of Physicians and Surgeons Pakistan. About 204 postgraduate medical trainee were enrolled in the study after taking written consent. All of the participants were working as a postgraduate medical trainee in different hospitals of Rawalpindi and Islamabad. A self-designed structured questionnaire containing 20 multiple choice questions regarding knowledge of epidemiology was given to all the participants. Knowledge of epidemiology was measured and compared with gender, hospital, and previous history of research. Statistical Package for the Social Sciences (SPSS), version 21.0 (IBM, Armonk, NY) was used for data analysis.

\section{Results}

Out of 204 participants, $46.1 \%$ participants were males while $53.9 \%$ were females. The mean age of the participant was $28.5 \pm 2.5$. Majority fo the trainees $(33.8 \%)$ were training in an Internal Medicine residency program. Most of the trainees (76\%) had average knowledge of epidemiology while $18.6 \%$ of the trainees had good knowledge. Only $17.6 \%$ had some experience of research projects in the past, but this was not related to knowledge of

Received 01/04/2018 Review began 02/04/2018 Review ended 02/05/2018 Published 02/08/2018

\section{(๑) Copyright 2018}

Shafi et al. This is an open access article distributed under the terms of the Creative Commons Attribution License CC-BY 3.0., which permits unrestricted use, distribution, and reproduction in any medium, provided the original author and source are credited. epidemiology $(p>0.05)$.

\section{Conclusion}

Only $18.6 \%$ of the postgraduate trainees had good knowledge regarding epidemiology and $76 \%$ had average knowledge. This knowledge did not relate to their gender, hospital settings, and previous experience of conducting research proposals and articles.

Categories: Medical Education, Public Health, Epidemiology/Public Health Keywords: epidemiology, post graduate trainee, evidence based medicine, medical education 


\section{Introduction}

Epidemiology is absolutely necessary for the understanding of disease etiology and prevention of disease by specific measures such as immunization and screening. In the era of evidencebased medicine (EBM), we all depend on the knowledge gained through epidemiological studies [1]. Majority of the doctors (95.5\%) believed that EBM is important for the practice of medicine [2]. Medical education is mostly aimed at preparing doctors to respond to the needs and requirements of sick individuals [3]. The main source of information for EBM is research. These research studies help in better management of the patients [4]. In a study done by Daher AM et al. on 138 students, $80.7 \%$ of the students believed that the subject of epidemiology plays a fundamental role in understanding and solving basic health issues [5].

Study of epidemiology teaches us how to design and carry out research studies. There are multiple study designs available to carry out research. According to a study, the most common study design was the cross-sectional study (40\%) followed by the retrospective study (18\%) and randomized controlled trial (8\%) [6]. Studies have shown that appropriately $30 \%$ to $90 \%$ of the studies have flaws in their designs and statistical analysis [4-5,7].

Students who are more involved in research during medical school are more likely to actively participate in postgraduate research activities. Prior undergraduate knowledge and experience of research can increase the understanding of research studies [8]. According to Khalid $\mathrm{M}$ et al., $91 \%$ of the students believed that research methodology should be part of the medical school curriculum. According to the participants in this study, deficiency in training courses (88.8\%), lack of supervisors (84.7\%), lack of time (72.3\%), and no funding support (54.1\%) were the main obstacles in doing research during medical schools [9]. Research experience during medical school can help the students by improving their abilities to do a proper literature review and also help them in doing a critical appraisal of articles which can lead the student to establish a good career and become a better resident and fellow [10]. A study done in Pakistan showed that out of 126 students from the third and fourth year; $76 \%$ of the student believed that epidemiology should be taught in the first two years of medical school [11].

It is important to evaluate the knowledge of epidemiology in postgraduate medical trainees as this is the time when we can train them and improve their knowledge and skills regarding epidemiology. Trainees who do not have sufficient knowledge regarding epidemiology are not able to conduct research activities and practice EBM [12]. The objective of this study was to determine the knowledge of epidemiology among postgraduate medical trainees. To the best of our knowledge, very few studies are available in our region regarding the evaluation of knowledge of epidemiology.

\section{Materials And Methods}

We carried out a cross-sectional study from January 2017 to June 2017 among postgraduate medical trainees working in hospitals of Rawalpindi and Islamabad. The participants were selected through the consecutive non-probability sampling technique. A total of 204 participants were included. The sample size of 204 was calculated using the World Health Organization (WHO) calculator keeping confidence level at 95\%, anticipated population proportion for knowledge of residents regarding epidemiology methods at $45.6 \%$ [4] and absolute precision at $7 \%$. Informed consent was obtained from all the participants. A selfdesigned structured questionnaire containing 20 multiple choice questions regarding the knowledge of epidemiology was given to all the participants. Cronbach's Alpha value for the questionnaire was found to be 0.87 .

The first part of the questionnaire compromised of six questions which were based on the demographic information of the participants. The first part covered questions regarding age, 
gender, hospital setting, the name of the medical school from where they graduated, year of training, and previous experience of conduction research. The second part of the questionnaire compromised of 20 multiple choice questions regarding knowledge about epidemiology. Questions with missing answer were considered incorrect. The total score of the second part was categorized into good, average, and poor. A score from zero to seven was considered as poor while a score from eight to fourteen and fifteen to twenty was considered as average and good, respectively. Each participant was given 20 min to answer the questions. The data collection was done under the supervision of the researchers.

The data of the study was analyzed using the Statistical Package for the Social Sciences (SPSS), version 21.0 (IBM, Armonk, NY). Quantitative variables like age were measured as the mean and standard deviation. Descriptive statistics were measured for qualitative variables. Chi-square test was applied to measure the association of knowledge with age, gender, hospital setting they were working in, the medical school from where they graduated, year of training and previous experience of conducting research. P- value $<0.05$ was taken as significant.

\section{Results}

About 204 respondents who had given informed consent were included in the study. The response rate was 100 . Out of 204 students; 94 (46.1\%) were males while 110 (53.9\%) were females. The mean age of the participants was $28.5 \pm 2.5$ years. About 144 (70.6\%) of the participants were doing the residency at public sector hospital while $60(29.4 \%)$ were doing the residency at private sector hospitals. Majority of the participants (total of $69 ; 33.8 \%$ ) were in their residency in internal medicine while $56(27.5 \%)$ participants were doing the residency in Surgery, 25 (12.3\%) in Gynecology and Obstetrics, 18 (8.8\%) in Pediatrics, 13 (6.4\%) in Opthalmology, 11 (5.4\%) in Dentistry, seven (3.4\%) in Pathology and five (2.5\%) in Otorhinolaryngology. Out of 204 trainees, 78 (38.2\%) and 111 (54.4\%) were in the first and second year of training while $13(6.4 \%)$ and 2 (1\%) were in the third and fourth year of training. About 157 (77\%) had graduated from their medical school one to five years ago while 42 (20.5\%) and five of them (2.5\%) had graduated from their medical school six to ten years ago and more than 10 years ago respectively. Majority $(121 ; 59.3 \%)$ of the participants had done their graduation from government colleges. Only 36 (17.6\%) of the postgraduate trainees had some experience of doing research projects.

Majority of the participants (155; 76\%) had average knowledge of epidemiology while 38 (18.6\%) had good and 11 (5.4\%) poor knowledge of epidemiology, respectively. This has been presented in Figure 1. 


\section{Cureus}

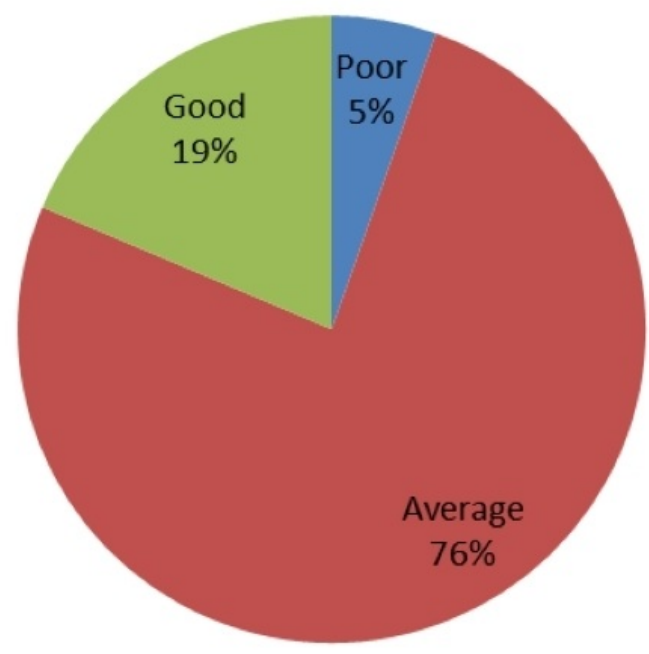

FIGURE 1: Knowledge of epidemiology among postgraduate medical trainees

None of the participants with a prior experience of research project had poor knowledge. There was no significant association ( $p$-value $>0.05$ ) between knowledge of epidemiology with respect to gender, type of hospital they were being trained, and previous experience of conducting any research project. This has been presented in Figure 2 and Figure 3.

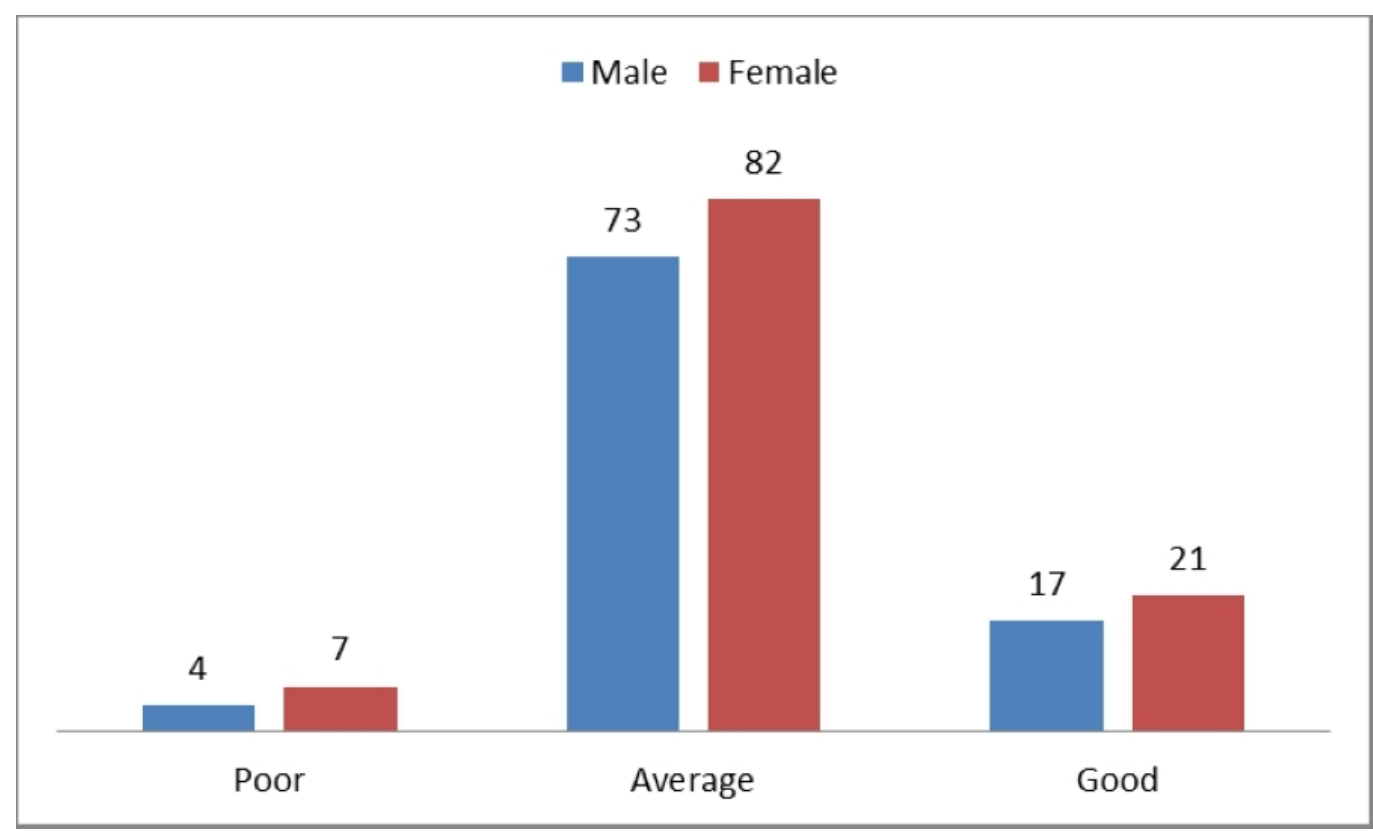

FIGURE 2: Gender-wise distribution of the knowledge of epidemiology among postgraduate medical trainees 


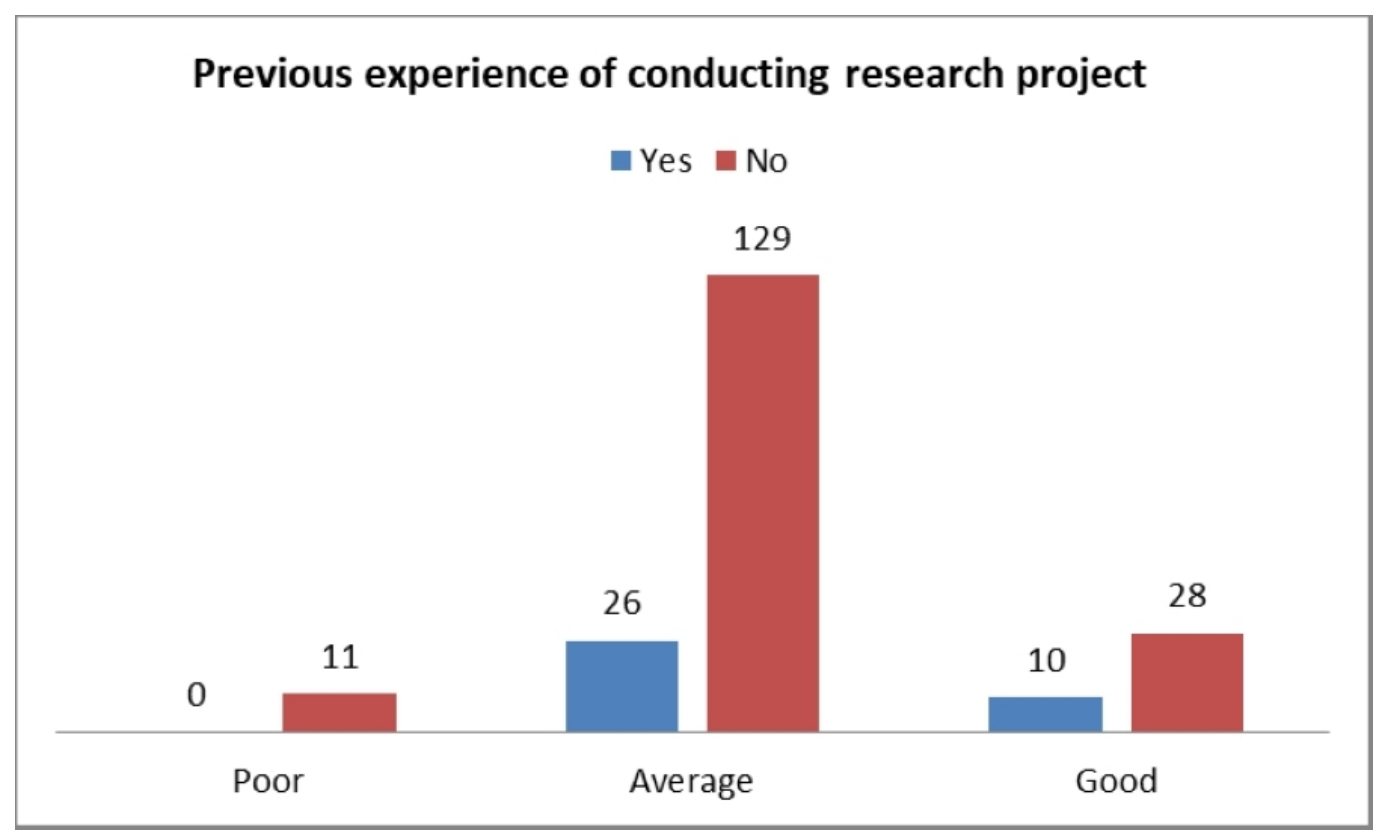

FIGURE 3: Knowledge of epidemiology among postgraduate medical trainees with respect to previous experience in research

\section{Discussion}

Our main objective of this research was to measure the knowledge of the postgraduate medical trainees regarding epidemiology. The response rate in our study was $100 \%$ as compared to other studies in which it was 76\% [8], 77\% [12] and 84.2\% [4]. Among 204 students in our research, $46.1 \%$ were male and $53.9 \%$ were female, showing more females participants as compared to males participants which is different as compared to the study done by Segal S [8] in which there were more male participants. Another study done showed a predominance of female participants (56\%) [12]. The mean age of the participants in this study was $27 \pm 7$ years (24-45 years). In our study, the mean age of the participants is $28.5 \pm 2.5$ years.

A study done by Zambudio AR et al. showed a similar portion of participants training in different specialties as compared to our study. According to the study by Zambudio AR, 47\% of the participants were training in internal medicine while $22 \%$ were training in surgery and $31 \%$ were training in central services; while specialty was not specified in the remaining $(0.6 \%)$ of the participants. Internal medicine was also the most common training specialty in another study conducted by Novack L et al. [4]. In terms of the year of residency, Novack L et al. showed $22 \%$ were in the first year, $25 \%$ in the second year, $26 \%$ in the third, $20 \%$ in the fourth, and $5 \%$ in the fifth year [4]. In our study, most of the trainees were in the first and second year.

There was no difference in the knowledge between male and female trainees which was rated as good, average and poor in males (18.08\% 77.6\%, 4.2 \%\%) and (19.09\%, 74.5\%, 6.3\%) females. This was comparable with the study conducted by Segal S [8]. According to a study done in India, $58 \%$ of the trainees had fairly good knowledge about epidemiology and research; and $76 \%$ of the participants agreed that teaching about research should be part of the training. This study also suggested that improvement in the medical education system is mandatory to flourish research culture [13]. This result was consistent with a study done in Pakistan where 
$70.9 \%$ of the participants wanted to engage in research activities but could not pursue it because of lack of training [14].

A study done at the Aga Khan Hospital in Pakistan concluded that out of 187 participants only 26.9\% had research experience during their residency program and limited time was the most commonly cited reason for lack of research activities [15]. In the same study, it was the concluded that residents had inadequate knowledge of research; the residents were of the opinion that the curriculum should be modified in order to incorporate meaningful research experience [15]. A study done in India concluded that the residents had inadequate knowledge regarding epidemiology but had a positive attitude towards learning [16]. In contrary, a study done in Iran showed that $77.8 \%$ of the residents had favorable knowledge but had a negative attitude towards further learning [17].

According to other studies, having a higher level of knowledge about epidemiology was associated with shorter elapsed time since graduation, a higher number of publications, and self-reported reading. A study concluded that $53.7 \%$ of the participants who regularly read articles had adequate knowledge regarding epidemiology as compared to $23.3 \%$ of the participants who did not do any reading (p-value <0.001) [4]. In our study, previous experience had no significant $(p>0.05$ ) effect on knowledge of epidemiology. According to a study done by Segal S et al., residents with prior experience of conducting research were more likely to participate in research projects during residency as compared to residents who did not have any prior experience of conduction research (p-value $<0.001)[8]$.

Inappropriate knowledge in our study was related to a low understanding of questions with regards to study design and statistical analysis. In order to conduct a good quality research, it is imperative to have a proper understanding of study designs and statistical analysis [18]. Research is fundamental for residency training but despite this fact, it has taken a back seat among residents. In a study conducted in Japan among physicians, it was concluded that training in clinical research is important for improving knowledge about epidemiology [19]. In Pakistan, research is in the initial stages and we are experiencing the same obstacles as experience by other third world countries. There is very limited research work due to poor research training [20].

\section{Conclusions}

Most of the participants had an average knowledge of epidemiology, which is the basis of research. Knowledge of epidemiology is highly important for future research projects in Pakistan. There is a dire need to change the curriculum of medical schools and residency training programs in order to promote a research culture.

\section{Additional Information Disclosures}

Human subjects: Consent was obtained by all participants in this study. College of Physicians and Surgeons Pakistan Institutional Review Board and Ethics Committee issued approval NA.

Animal subjects: All authors have confirmed that this study did not involve animal subjects or tissue. Conflicts of interest: In compliance with the ICMJE uniform disclosure form, all authors declare the following: Payment/services info: All authors have declared that no financial support was received from any organization for the submitted work. Financial relationships: All authors have declared that they have no financial relationships at present or within the previous three years with any organizations that might have an interest in the submitted work. Other relationships: All authors have declared that there are no other relationships or activities that could appear to have influenced the submitted work. 


\section{References}

1. Blair M: Taking a population perspective on child health . Arch Dis Child. 2000, 83:7-9. 10.1136/adc.83.1.7

2. Godwin M, Seguin R: Critical appraisal skills of family physicians in Ontario, Canada . BMC Med Educ. 2003, 3:10. 10.1186/1472-6920-3-10

3. Moffat M, Sinclair HK, Cleland JA, Smith WC, Taylor RJ: Epidemiology teaching: student and tutor perceptions. Med Teach. 2004, 26:691-5. 10.1080/01421590400013537

4. Novack L, Jotkowitz A, Knyazer B, Novack V: Evidence-based medicine: assessment of knowledge of basic epidemiological and research methods among medical doctors. Postgrad Med J. 2006, 82:817-822. 10.1136/pgmj.2006.049262

5. Daher AM, Amin F: Assessing the perceptions of a biostatistics and epidemiology module: views of Year 2 medical students from a Malaysian university. A cross-sectional survey. BMC Med Educ. 2010, 10:34. 10.1186/1472-6920-10-34

6. Akhtar S, Shah SWA, Rafiq M, Khan A: Research design and statistical methods in Pakistan Journal of Medical Sciences (PJMS). Pak J Med Sci. 2016, 32:151-154. 10.12669/pjms.321.9033

7. Young J: Understanding statistical analysis in the surgical literature: some key concepts . ANZ J Surg. 2009, 79:398-403. 10.1111/j.1445-2197.2009.04900.x

8. Segal S, Lloyd T, Houts PS, et al.: The association between students research involvement in medical school and their postgraduate medical activities. Acad Med. 1990, 65:530-533.

9. Alghamdi KM, Moussa NA, Alessa DS, Alothimeen N, Al-Saud AS: Perceptions, attitudes and practices toward research among senior medical students. Saudi Pharm J. 2014, 22:113-117. 10.1016/j.jsps.2013.02.006

10. Brown AM, Chipps TM, Gebretsadik T, et al.: Training the next generation of physician researchers - Vanderbilt Medical Scholars Program. BMC Med Educ. 2018, 18:5. 10.1186/s12909-017-1103-0

11. Ahmad F, Zehra N, Omair A, Anjum Q: Students' opinion regarding application of epidemiology, biostatistics and survey methodology courses in medical research. J Pak Med Assoc. 2009, 59:307-310.

12. Kuhnigk O, Böthern AM, Reimer J, et al.: Benefits and pitfalls of scientific research during undergraduate medical education. GMS Z Med Ausbild. 2010, 27:Doc72. 10.3205/zma000709

13. Pawar DB, Gawde SR, Marathe PA: Awareness about medical research among resident doctors in a tertiary care hospital: a cross-sectional survey. Perspect Clin Res. 2012, 3:57-61. 10.4103/2229-3485.96446

14. Aslam F, Qayyum MA, Mahmud H, Qasim R, Haque IU: Attitudes and practices of postgraduate medical trainees towards research--a snapshot from Faisalabad. J Pak Med Assoc. 2004, 54:534-6.

15. Khan H, Khan S, Iqbal A: Knowledge, attitudes and practices around health research: the perspective of physicians-in-training in Pakistan. BMC Med Educ. 2009, 9:46. 10.1186/14726920-9-46

16. Giri PA, Bangal VB, Phalke DB: Knowledge, attitude and practices towards medical research amongst the postgraduate students of Pravara Institute of Medical Sciences University of Central India. J Family Med Prim Care. 2014, 3:22-24. 10.4103/2249-4863.130263

17. Memarpour M, Fard AP,Ghasemi R: Evaluation of attitude to, knowledge of and barriers toward research among medical science students. Asia Pac Fam Med. 2015, 14:1. 10.1186/s12930-015-0019-2

18. Jin Z, Yu D, Zhang L, et al.: A retrospective survey of research design and statistical analyses in selected Chinese medical journals in 1998 and 2008. PLoS One. 2010, 5:e10822. 10.1371/journal.pone.0010822

19. Sumi E, Murayama T, Yokode M: A survey of attitudes toward clinical research among physicians at Kyoto University Hospital. BMC Med Educ. 2009, 9:75. 10.1186/1472-6920-9-75

20. Sabzwari S, Kauser S, Khuwaja AK: Experiences, attitudes and barriers towards research amongst junior faculty of Pakistani medical universities. BMC Med Educ. 2009, 9:68. $10.1186 / 1472-6920-9-68$ 